\title{
Global mismatches in aboveground and belowground biodiversity
}

\section{Cameron, Erin K.}

$2019-10$

Cameron , E K, Martins , I S , Lavelle , P , Mathieu , J , Tedersoo , L , Bahram , M , Gottschall , F , Guerra , C A , Hines , J , Patoine , G , Siebert , J , Winter , M , Cesarz , S , Ferlian , O , Kreft , H , Lovejoy , T E , Montanarella , L, Orgiazzi , A, Pereira , H M , Phillips , H R P , Settele , J , Wall , D H \& Eisenhauer , N 2019, ' Global mismatches in aboveground and belowground biodiversity ' , Conservation Biology , vol. 33 , no. 5 , pp. 1187-1192 . https://doi.org/10.1111/cobi.13311

http://hdl.handle.net/10138/313248

https://doi.org/10.1111/cobi.13311

unspecified

acceptedVersion

Downloaded from Helda, University of Helsinki institutional repository.

This is an electronic reprint of the original article.

This reprint may differ from the original in pagination and typographic detail.

Please cite the original version. 


\section{Global mismatches in aboveground and belowground biodiversity}

Erin K. Cameron ${ }^{1,2^{*}}$, Inês S. Martins ${ }^{3,4}$, Patrick Lavelle ${ }^{5,6,7}$, Jérôme Mathieu ${ }^{8,9}$, Leho Tedersoo $^{10}$, Mohammad Bahram ${ }^{11}$, Felix Gottschall ${ }^{3,12}$, Carlos A. Guerra, 4 , Jes Hines ${ }^{3,12}$, Guillaume Patoine $^{3,13}$, Julia Siebert ${ }^{3,12}$, Marten Winter ${ }^{3}$, Simone Cesarz ${ }^{3,12}$, Olga Ferlian ${ }^{3,12}$, Holger Kreft ${ }^{14}$, Thomas E. Lovejoy ${ }^{15}$, Luca Montanarella ${ }^{16}$, Alberto Orgiazzi ${ }^{16}$, Henrique M. Pereira $^{3,4,17}$, Helen R. P. Phillips ${ }^{3,12}$, Josef Settele ${ }^{3,18,19}$, Diana H. Wall ${ }^{20,21}$, Nico Eisenhauer ${ }^{3,}$ 12

Affiliations:

${ }^{1}$ Faculty of Biological and Environmental Sciences, Post Office Box 65, Fl 00014, University of Helsinki, Finland.

${ }^{2}$ Department of Environmental Science, Saint Mary's University, Halifax, Nova Scotia, Canada

${ }^{3}$ German Centre for Integrative Biodiversity Research (iDiv) Halle-Jena-Leipzig, Deutscher Platz 5e, 04103, Leipzig, Germany.

${ }^{4}$ Institute of Biology, Martin Luther University Halle-Wittenberg, Am Kirchtor 1, 06108, Halle (Saale), Germany.

${ }^{5}$ UPMC Université Paris 06, iEES Paris, 32 Av. Henri Varagnat, 93143 Bondy Cedex, France.

${ }^{6}$ IRD, iEES Paris, Centre IRD Ile de France, 32 Av. Henri Varagnat, 93143 Bondy Cedex, France.

${ }^{7}$ Centro Internacional de Agricultura Tropical (CIAT), TSBF_LAC, ap aereo 6713, Cali, Colombia.

${ }^{8}$ Sorbonne Universitiés, UPMC Univ. Paris 06, IRD, CNRS, INRA, UPEC, University Paris Diderot.

${ }^{9}$ Institute of Ecology and Environmental Sciences, iEES Paris, 4 place Jussieu, 75005 Paris, France.

${ }^{10}$ Natural History Museum, University of Tartu, 14A Ravila, 50411 Tartu, Estonia.

This article has been accepted for publication and undergone full peer review but has not been through the copyediting, typesetting, pagination and proofreading process, which may lead to differences between this version and the Version of Record. Please cite this article as doi: 10.1111/cobi.13311. 
${ }^{11}$ Department of Ecology, Swedish University of Agricultural Sciences, Ulls väg 16, 75651 Uppsala, Sweden

${ }^{12}$ Institute of Biology, Leipzig University, Deutscher Platz 5e, 04103, Leipzig, Germany.

${ }^{13}$ Center for Environmental Research and Technology, General and Theoretical Ecology, University of Bremen, Leobener Str, 28359 Bremen, Germany.

${ }^{14}$ Biodiversity, Macroecology \& Biogeography, University of Goettingen, Göttingen, Germany.

${ }^{15}$ Department of Environmental Science and Policy, George Mason University, Fairfax, VA 22030, USA

${ }^{16}$ European Commission, Joint Research Centre (JRC), Sustainable Resources Directorate, Land Resources Unit, Ispra, Italy.

${ }^{17}$ Infraestruturas de Portugal Biodiversity Chair, CiBiO/InBIO, Universidade do Porto, 4485661, Vairão, Portugal.

${ }^{18}$ Helmholtz Centre for Environmental Research, UFZ, Department of Community Ecology, Theodor-Lieser-Str. 4, 06120 Halle, Germany

${ }^{19}$ Institute of Biological Sciences, University of the Philippines Los Baños, College, 4031 Laguna, Philippines

${ }^{20}$ Department of Biology, Colorado State University, Fort Collins, CO, USA.

${ }^{21}$ School of Global Environmental Sustainability, Colorado State University, Fort Collins, CO, USA.

*Correspondence to: Erin Cameron, Department of Environmental Science, Saint Mary's University, Halifax, Nova Scotia, Canada erin.cameron@smu.ca

Running head: Soil biodiversity

Keywords: aboveground-belowground; bacteria; fungi; global patterns; macrofauna; mismatch; policy; soil biodiversity 
Article impact statement:

Given the importance of soil biodiversity for human well-being, it should be considered in conservation policy and actions.

\section{Abstract}

Human activities are accelerating global biodiversity change and have resulted in severely threatened ecosystem services. A large proportion of terrestrial biodiversity is harbored by soil, but soil biodiversity has been neglected from many global biodiversity assessments and conservation actions, and our understanding of global patterns of soil biodiversity remains limited. In particular, the extent to which hotspots and coldspots of aboveground and soil biodiversity overlap is not clear. We examined global patterns of overlap by mapping indices of aboveground (mammals, birds, amphibians, vascular plants) and soil (bacteria, fungi, macrofauna) biodiversity. Our analysis indicated that areas of mismatch between aboveground and soil biodiversity covered $27 \%$ of the Earth's terrestrial surface. The temperate broadleaf and mixed forests biome had the highest proportion of grid cells with high aboveground biodiversity but low soil biodiversity, while the boreal and tundra biomes had higher soil biodiversity but low aboveground biodiversity. While more data on soil biodiversity is needed, both to cover geographic gaps and to include additional taxa, our results suggest that protecting aboveground biodiversity may not sufficiently reduce threats to soil biodiversity. Given the functional importance of soil biodiversity and the role of soils for human well-being, soil biodiversity should be further considered in policy agendas and 
conservation actions by adapting management practices to sustain soil biodiversity and considering soil biodiversity when designing protected areas.

\section{Introduction}

The ability of humans to address some of the key challenges of our times, such as a lack of food security and water purification, depends in part on our interactions with soil. Soils are essential for maintaining a wide range of highly important ecosystem services, such as nutrient cycling, carbon storage, and medical resources (Wall et al. 2013; Bardgett \& van der Putten 2014). Yet soil biodiversity faces dramatic declines due to human activities, particularly land-use change and agricultural intensification (Tsiafouli et al. 2015). This is alarming given the substantial global gaps in knowledge of soil biodiversity (Phillips et al. 2017; Cameron et al. 2018), which have likely been a major factor limiting attempts to address declines in soil biodiversity with policy at large scales. Since the release of the first global report on soil biodiversity (Orgiazzi et al. 2016), data availability has been improving.

Building on this, as well as existing knowledge of aboveground biodiversity, we examine whether the typical focus on conserving aboveground taxa also serves the purpose of protecting the functionally important but less visible soil biodiversity. Previous research suggests that hotspots of aboveground (Myers et al. 2000) and soil biodiversity may not correspond due to different factors (e.g., soil pH) acting as key drivers of biogeographical 
patterns belowground (Fierer \& Jackson 2006; Parker 2010). To this end, we compare commonly used vertebrate and plant datasets with recent global datasets on soil taxa (macrofauna, fungi, and bacteria). We also provide recommendations for incorporating soil biodiversity into conservation planning and global policy targets.

\section{Methods}

To examine the overlap between aboveground and soil biodiversity, we created a global map (Fig. 1; see detailed methods in Appendix S1). An aboveground biodiversity index was created by combining global datasets of aboveground species richness of vertebrates (mammals, birds, and amphibians; IUCN 2012; BirdLife International 2011) and vascular plants (Kreft \& Jetz 2007). While plants are not strictly aboveground organisms, we considered them as such, because plant diversity was assessed aboveground.

A soil biodiversity index was similarly created by harmonizing richness data of three of the largest global datasets available on soil biodiversity - soil macrofauna (Mathieu \& Lavelle 2016; $n=2163$ sites), fungi (Tedersoo et al. 2014; $n=365$ sites), and bacteria (Bahram et al. 2018; $n=197$ sites). Soil macrofauna groups included earthworms, ants, termites, spiders, millipedes, centipedes, isopods, fly larvae, cockroaches and mantids, moth and butterfly larvae, grasshoppers and crickets, gastropods, beetles, and other macrofauna (Mathieu \& Lavelle 2016), while the fungal and bacterial datasets were based on metabarcoding the 
ITS2 and 16S regions, respectively (Tedersoo et al. 2014; Bahram et al. 2018). These three groups of taxa represent an important subset of all soil organisms but do not include all groups of soil biota. Additional global datasets on soil bacteria are now being published (Delgado-Baquerizo et al. 2018; Ramirez et al. 2018), and datasets on other soil taxa are now being compiled, which should be incorporated into more detailed future analyses of mismatches of aboveground and soil biodiversity.

\section{Results}

Our analyses reveal that areas of mismatch between aboveground and soil biodiversity cover $27 \%$ of the terrestrial surface of the Earth. Regions where aboveground biodiversity is high but soil biodiversity is low are located in parts of Colombia, Brazil, Portugal, Spain, Eastern Europe, west-central Africa, Malaysia, Indonesia, Papua New Guinea, and the Midwestern United States (Fig. 1). Temperate broadleaf and mixed forests is the biome with the highest proportion of grid cells having high aboveground biodiversity but low soil biodiversity (Table S1). We find the opposite pattern of intermediate to high soil biodiversity but low aboveground biodiversity in parts of India, northern China, and northern Australia (Fig. 1). Additionally, soil biodiversity remains at an intermediate level but aboveground biodiversity is low in a large portion of the globe's northern regions, such as the boreal and tundra regions of Canada and Russia. Interestingly, aboveground biodiversity continues to decrease towards the North Pole even at high latitudes, but soil biodiversity reaches a plateau (e.g., Tedersoo et al. 2014, Bahram et al. 2018). 
Only $37 \%$ of the areas with the highest (top $25 \%$ ) aboveground or soil biodiversity overlap. Thus, if we focus on conserving only areas with the highest aboveground biodiversity, we risk the degradation of more than half of the areas with the greatest soil biodiversity. Nonetheless, joint hotspot and coldspot areas occur across $73 \%$ of terrestrial ecosystems. We find joint hotspots occur in the equatorial regions of South America, Central America, Central Africa, and parts of Southeast Asia, and in particular in the tropical and subtropical moist broadleaf forests biome (Fig. 1; Table S1). In contrast, joint coldspots mostly occur in deserts (e.g., the Sahara), as well as in parts of the boreal forest/taiga biome.

The standard deviation around the mean biodiversity values is higher for soil biodiversity than aboveground biodiversity (Fig. S1). Standard deviation values for soil biodiversity are highest in parts of the Amazon, central Africa, central Asia, Malaysia, and Indonesia, which are some of the regions where soil biodiversity data is particularly lacking. Most of the observed patterns remain similar when examining subsets of taxa (Fig. S2). For example, when soil macrofauna and aboveground biodiversity are mapped (i.e., soil microbes are not included), the only substantial change is that part of west-central Africa becomes a joint soil and aboveground biodiversity hotspot, rather than having high aboveground biodiversity but lower soil biodiversity. Mapping soil microbial biodiversity in relation to aboveground biodiversity results in larger differences; in particular, areas that were joint hotspots in South America, central Africa, and Madagascar when both soil macrofauna and microbial 
data were mapped together become aboveground biodiversity hotspots with lower soil biodiversity. Maps of plant biodiversity versus aboveground biodiversity and vertebrate biodiversity versus aboveground biodiversity are again highly similar to Fig. 1.

\section{Discussion}

The mismatches we report here suggest that conserving aboveground biodiversity will not be sufficient to protect soil biodiversity, and thus policy changes and conservation actions must be taken to manage key threats. Our understanding of global patterns is restricted by substantial soil biodiversity data gaps in key regions such as Africa and Russia, in particular central Africa and Siberia (Bahram et al. 2018; Cameron et al. 2018), as well as a lack of global datasets on taxa such as microarthropods and nematodes. The lack of data on microbes aboveground (e.g., on leaves) and parasites in general, which are also not typically considered in conservation efforts, is another major gap in our understanding.

An additional limitation of our analysis is that the datasets that are currently available differ in taxonomic resolution (e.g., the macrofauna dataset included data on groups of macrofauna such as earthworms, rather than data at the species-level or operational taxonomic unit (OTU)-level), which may make comparisons difficult. Also, molecular methods were used to obtain microbial data (which may contain DNA of taxa that are no longer alive), while classic taxonomic methods were used for the other taxa (which mostly 
cover active organisms, with no resting stages for example). In fact, the analysis where soil microbial biodiversity was overlain in relation to aboveground biodiversity (Fig. S2) differed more substantially from the all-taxa analysis (Fig. 1) than did the other analyses which examined separate groups of taxa (also shown in Fig. S2). This issue should be considered in future analyses of aboveground-soil biodiversity mismatches as data availability improves.

Nonetheless, some general recommendations can be drawn from our analysis, combined with previous research. Intensive human exploitation and soil degradation are critical threats in regions with high soil biodiversity, with risks being especially high in agricultural areas (Tsiafouli et al. 2015). For example, soil biodiversity is relatively high in India, especially along the northeast border which is a joint hotspot for aboveground and soil biodiversity (Fig. 1), but this same region also has one of the highest densities of cropland in the world (Klein Goldewijk et al. 2010). Agricultural intensification impacts soil biodiversity across functional groups through a range of management practices, such as application of high levels of pesticides and fertilizers as well as intensive tillage (Tsiafouli et al. 2015; FAO \& ITPS 2015). To minimize impacts, reduced and no-till systems should be implemented where possible, pesticide and fertilizer applications should be reduced, and reclamation of degraded land should be increased.

This article is protected by copyright. All rights reserved. 
Threats to soil biodiversity should also be managed by considering soil biodiversity in protected areas planning and conservation prioritization (Parker 2010, Orgiazzi et al. 2016). This is likely to be most feasible in regions where relatively high soil biodiversity coincides with low human population densities but which are also threatened by future resource extraction. Specifically, to protect soil biodiversity hotspots while minimizing conflicts with human land use, designation of new or expansion of existing protected areas in boreal and tundra regions (where soil biodiversity is intermediate and aboveground biodiversity is low, Fig. 1) should be a top priority, given the pronounced climate change expected (IPCC 2013), and the functional importance for carbon storage of those regions (Tarnocai 2009). These regions have soil high in organic matter in contrast to the thinner organic soil layer found in tropical forests, which may help to support high soil biodiversity but not necessarily aboveground biodiversity. Furthermore, these rich organic soils are critical for global carbon dynamics and soil biodiversity contributes to these dynamics. Any measures to conserve soil (as well as aboveground) biodiversity hotspots worldwide will be compromised without corresponding action to address climate change, and major national and international efforts focused on managing both land use and climate change are required.

The compelling evidence of the strong links between soil biodiversity and provisioning of ecosystem services (Wall 2004, Wall et al. 2013) needs to be better translated into policies. For example, soil biodiversity should be incorporated more explicitly in global initiatives, such as IPBES (Intergovernmental Science-Policy Platform on Biodiversity and Ecosystem 
Services) and the $2020+/ 2030$ strategy of the Convention on Biological Diversity (CBD). As well, the United Nations Convention to Combat Desertification (UNCCD) recently endorsed the Scientific Conceptual Framework for Land Degradation Neutrality (LDN), which calls for no decrease in the amount and quality of land resources within specified temporal and spatial scales (Orr et al. 2017). Reclamation to restore degraded lands, as called for in this framework, benefits both soil biodiversity and ecosystem functioning.

In addition to participating in global assessments, further work is needed to collect data on soil biodiversity patterns, such as endemism, and to determine how knowledge on the relationship between soil biodiversity and ecosystem functioning can be scaled up from the plot-level to the global scale. The critical next step will be to use these large-scale datasets, developed through synthesis or assessments, to determine what to conserve in order to maintain vital ecosystem services. Cooperation with policy makers and conservation biologists is essential for this to be successful.

In conclusion, the neglect of soil biodiversity in policy agendas and conservation debates thus far is decreasing and can be further corrected in the future by: (1) filling data gaps in our knowledge of global distributions of soil taxa to allow improved mapping, (2) adapting management practices to sustain soil biodiversity in the long-term (e.g., in relation to agriculture (Tsiafouli et al. 2015)), (3) considering soil biodiversity when designing or 
enlarging protected areas (e.g., in boreal and tundra regions), and (4) incorporating knowledge of soil biodiversity into local to global policies and biodiversity and ecosystem services assessments.

\section{Acknowledgments}

We thank all contributors to the Macrofauna database, especially E. Lapied, G. Brown, and C. Fragoso. Financial support came from the European Research Council (ERC Starting Grant to NE; grant agreement no 677232) and the German Centre for Integrative Biodiversity Research (iDiv) Halle-Jena-Leipzig, funded by the German Research Foundation (FZT 118). EKC received support from the Academy of Finland (285882) and the Natural Sciences and Engineering Research Council of Canada (postdoctoral fellowship) and MB received funding from the Swedish Research Council (VR grant 2017-05019). CAG is supported by the EU Horizon 2020 research and innovation programme (grant agreement no. 641762ECOPOTENTIAL).

\section{Literature Cited}

Bahram M, et al. 2018. Structure and function of the global topsoil microbiome. Nature $\mathbf{5 6 0}$ : 233-237.

Bardgett RD, van der Putten WH. 2014. Belowground biodiversity and ecosystem functioning. Nature 515: 505-511.

This article is protected by copyright. All rights reserved. 
BirdLife International, NatureServe. 2011. Bird species distribution maps of the world.

BirdLife International, Cambridge, UK and NatureServe, Arlington, USA.

Cameron EK, et al. 2018. Global gaps in soil biodiversity data. Nature Ecology \& Evolution 2: 1042-1043.

Delgado-Baquerizo M, Oliverio AM, Brewer TE, Benavent-Gonzalez A, Eldridge DJ, Bardgett RD, Maestre FT, Singh BK, Fierer N. 2018. A global atlas of the dominant bacteria found in soil. Science 359: 320-325.

FAO and ITPS. 2015. Status of the World's Soil Resources (SWSR) - Main Report. Food and Agriculture Organization of the United Nations and Intergovernmental Technical Panel on Soils, Rome, Italy. Available from http://www.fao.org/3/a-i5199e.pdf (accessed December 2017).

IPCC. 2013. Climate Change 2013: The Physical Science Basis. Contribution of Working Group I to the Fifth Assessment Report of the Intergovernmental Panel on Climate Change. Stocker TF, et al. (eds). Cambridge University Press, Cambridge, United Kingdom and New York, NY, USA.

IUCN. 2012. The IUCN Red List of Threatened Species. Version 2012.1. http://www.iucnredlist.org.

Klein Godewijk K, Beusen A, van Drecht G, de Vos M. 2011. The HYDE 3.1 spatially explicit database of human-induced global land-use change over the past 12,000 years. Global Ecology and Biogeography 20: 73-86.

This article is protected by copyright. All rights reserved. 
Kreft H, Jetz W. 2007. Global patterns and determinants of vascular plant diversity.

Proceedings of the National Academy of Sciences 104: 5925-5930.

Mathieu J, Lavelle P. 2016. First map of soil macrofauna biodiversity at global scale. Page 71 in in Orgiazzi A, et al. Global Soil Biodiversity Atlas. Publications Office of the European Union, Luxembourg.

Myers N, Mittermeier RA, Mittermeier CG, da Fonseca GA, Kent J. 2000. Biodiversity hotspots for conservation priorities. Nature 403: 853-858.

Orgiazzi A, et al. (eds) 2016. Global Soil Biodiversity Atlas. Publications Office of the European Union.

Orr BJ, et al. 2017. Scientific Conceptual Framework for Land Degradation Neutrality. A Report of the Science-Policy Interface. United Nations Convention to Combat Desertification (UNCCD), Bonn, Germany.

Parker SS. 2010. Buried treasure: soil biodiversity and conservation. Biodiversity and Conservation 19: 3743-3756.

Phillips HRP, et al. 2017. Red list of a black box. Nature Ecology \& Evolution 1: 0103.

Ramirez KS, et al. 2018. Detecting macroecological patterns in bacterial communities across independent studies of global soils. Nature Microbiology 3: 189-196.

This article is protected by copyright. All rights reserved. 
Tarnocai C, Canadell JG, Schuur EAG, Kuhry P, Mazhitova G, Zimov S. 2009. Soil organic carbon pools in the northern circumpolar permafrost region. Global Biogeochemical Cycles 23: GB2023. https://doi.org/10.1029/2008GB003327

Tedersoo L, et al. 2014. Global diversity and geography of soil fungi. Science 346: 1256688. DOI: 10.1126/science.1256688.

Tsiafouli MA, et al. 2015. Intensive agriculture reduces soil biodiversity across Europe. Glob. Change Biol. 21: 973-985.

Wall DH, Bardgett RD, Behan-Pelletier V, Herrick JE, Jones TH. (eds). 2013. Soil Ecology and Ecosystem Services. Oxford University Press, Oxford.

Wall DH. 2004. Sustaining biodiversity and ecosystem services in soils and sediments. SCOPE Series. Island Press, Washington, DC. 

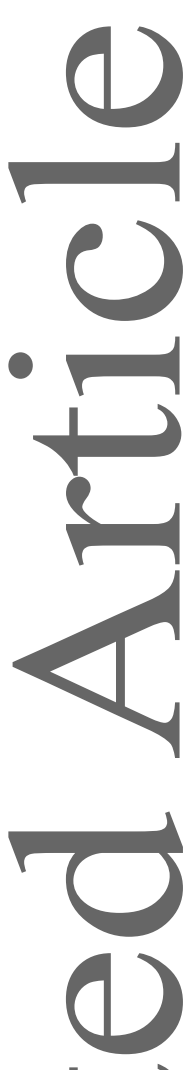

.

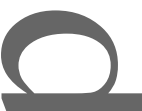

with insufficient data. Color scales are based on quantile intervals with each class containing an equal number of features.

Fig. 1. Global distribution of the overlap between aboveground (mammals, birds,

amphibians, plants) and soil (macrofauna, fungi, bacteria) biodiversity. Dark areas have high aboveground and soil biodiversity; bright yellow areas have high aboveground but low soil biodiversity; bright blue areas have low aboveground but high soil biodiversity; and light areas have low aboveground and soil biodiversity. Gray areas represent terrestrial areas
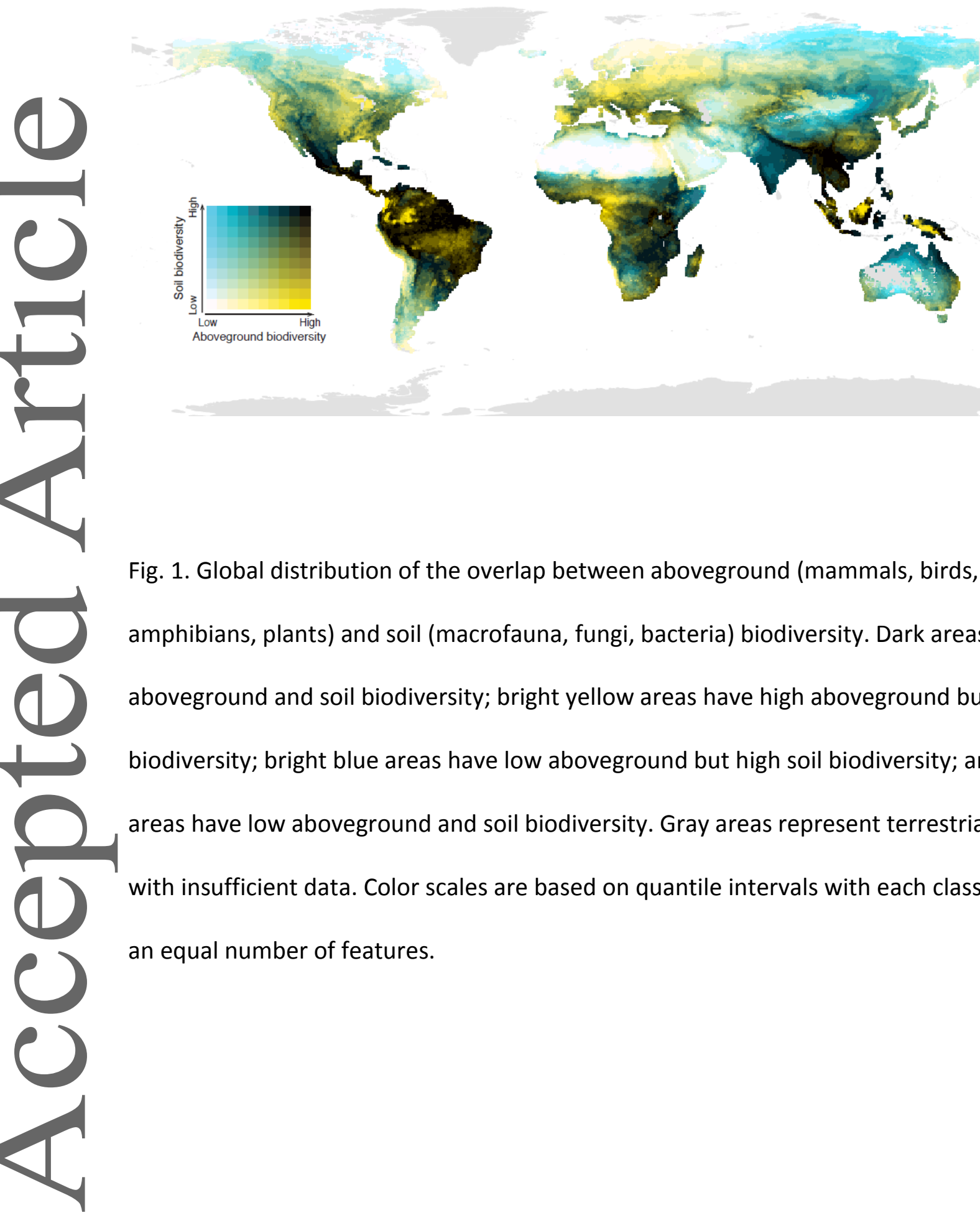

This article is protected by copyright. All rights reserved. 